\title{
Occurrence of the Retromolar Foramen in Dry Mandibles of South-Eastern Part of India: A Morphological Study with Review of the Literature
}

\author{
Bhagath Kumar Potu, ${ }^{1}$ Vinod Kumar, ${ }^{2}$ Abdel-Halim Salem, ${ }^{1,3}$ and Marwan Abu-Hijleh ${ }^{1}$ \\ ${ }^{1}$ Department of Anatomy, College of Medicine and Medical Sciences, Arabian Gulf University, 26671 Manama, Bahrain \\ ${ }^{2}$ Department of Anatomy, Sapthagiri Institute of Medical Sciences \& Research Center, Bangalore 560010, India \\ ${ }^{3}$ Department of Anatomy, Faculty of Medicine, Suez Canal University, Ismailia 4111, Egypt \\ Correspondence should be addressed to Bhagath Kumar Potu; potubk@agu.edu.bh
}

Received 24 June 2014; Accepted 31 August 2014; Published 29 September 2014

Academic Editor: Levent Sarikcioglu

Copyright (C) 2014 Bhagath Kumar Potu et al. This is an open access article distributed under the Creative Commons Attribution License, which permits unrestricted use, distribution, and reproduction in any medium, provided the original work is properly cited.

\begin{abstract}
The retromolar foramen (RMF) is a rare anatomical structure situated in the retromolar fossa behind the third molar tooth. When it is present, the foramen is connected with the mandibular canal and is believed to transmit neurovascular structures that provide accessory source to the mandibular molars and the buccal area. Reports from the literature show that the presence of RMF could pose a challenge in complete blockage of the inferior alveolar nerve during mandibular surgeries. We report the incidence of retromolar foramen from ninety-four dry mandibles of south-eastern part of Karnataka State, India. The foramen was observed in 11 mandibles out of 94 included in the study (11.7\%). In three mandibles, the foramen was present bilaterally (3.2\%) and in three it was on the left side $(3.2 \%)$ and in five it was on the right side (5.3\%). For the first time, we also measured the dimensions of the retromolar area and distance of the foramen from third molar tooth to understand its risks during the surgical extraction of the lower third molar tooth. A thorough review of the literature has also been done to compare the present findings with the studies reported from the various populations.
\end{abstract}

\section{Introduction}

The RMF is an inconstant foramen situated in the central portion of the retromolar fossa which is bounded by the anterior border of ramus of the mandible and temporal crest. The foramen receives a canal of variable depth that normally arises from the mandibular canal behind the lower third molar, which is regarded as the retromolar canal (RMC) [1]. Normal morphological findings of the human mandible and its possible variations that occur have attracted special interest in the recent years in the field of odontostomatological surgeries [2]. One such anatomical variation which draws special attention in clinical dental practice is the RMF in the retromolar trigone (RMT). The trigone is bounded medially by temporal crest, laterally by the anterior border of the ramus, and anteriorly by the base of third molar tooth [3]. The RMF has generally been neglected in anatomical text books and this has been rarely studied or reviewed in the dental literature. The frequency of RMF has been reported in different populations showing a wide varying incidence between $3.2 \%$ and $72 \%$ [4-20]. However, there is no recent systematic study conducted on the RMF occurrence in the south-eastern part of Karnataka, India, with the morphometry we adopted; hence we report our findings on the occurrence of RMF in this population.

\section{Material and Methods}

In this study, all available 94 dry, fully ossified adult mandibles from the Department of Anatomy, Sapthagiri Institute of Medical Sciences and Research Center, Bangalore, southeastern part of India, were included. In 94 dry mandibles, the presence of RMF was noted and the lengths of the anterior, medial, and lateral boundaries of the retromolar trigone were carefully measured using a digital vernier caliper. Wherever 
TABLE 1: Dimensions of the boundaries of retromolar trigone in the mandibles with presence of RMF.

\begin{tabular}{|c|c|c|c|c|}
\hline \multirow{2}{*}{$\begin{array}{l}\text { Mandible number } \\
\text { with RMF }\end{array}$} & \multirow[t]{2}{*}{ Side } & \multicolumn{3}{|c|}{$\begin{array}{c}\text { Borders of the retromolar } \\
\text { trigone }(\mathrm{mm})\end{array}$} \\
\hline & & Medial & Lateral & Anterior \\
\hline 9 & Right & 32 & 35 & 14 \\
\hline 26 & Left & 35 & 35 & 16 \\
\hline 32 & Right & 29 & 32 & 10 \\
\hline 48 & Left & 46 & 41 & 12 \\
\hline 51 & Left & 38 & 40 & 9 \\
\hline 58 & Right & 43 & 46 & 11 \\
\hline 58 & Left & 41 & 37 & 12 \\
\hline 64 & Right & 42 & 38 & 15 \\
\hline 72 & Right & 43 & 38 & 14 \\
\hline 80 & Right & 34 & 35 & 12 \\
\hline 88 & Right & 34 & 30 & 12 \\
\hline 88 & Left & 30 & 32 & 13 \\
\hline 91 & Right & 37 & 35 & 12 \\
\hline 91 & Left & 36 & 35 & 10 \\
\hline Mean \pm SD & & $37.14 \pm 5.23$ & $36.36 \pm 4.13$ & $12.29 \pm 1.98$ \\
\hline Min-Max & & $29-46$ & $30-46$ & 9-16 \\
\hline
\end{tabular}

foramina were noticed, the distance of the RMF from the posterior border of socket for third molar, anterior border of the ramus, and lingula were also measured, respectively. All the measurements were performed independently by two individuals (Bhagath Kumar Potu and Vinod Kumar) for three times and averaged to arrive at accurate data. The mean, range, and standard deviation of all the measurements were statistically analyzed.

\section{Results}

Retromolar foramen (RMF) was observed in 11 mandibles out of 94 included in the study (11.7\%). In three mandibles, the foramen was observed bilaterally (3.2\%) and in another three it was on the left side (3.2\%) and in another five it was on the right side $(5.3 \%)$. It was found that the length of medial boundary of the retromolar trigone varies between 19 and $30 \mathrm{~mm}$, the lateral boundary varies between 21 and $32 \mathrm{~mm}$, and the anterior boundary varies between 9 and $16 \mathrm{~mm}$ (Table 1). The RMF in our study was mostly located in medial aspect of the retromolar fossa close to lingula (Figure 1). The distances of the RMF from the posterior border of socket for third molar, anterior border of the ramus, and lingula are shown in Table 2. It was seen that the distance of RMF from third molar socket, from the anterior border of ramus, and also from the lingula varies between 4 and $11 \mathrm{~mm}, 3$ and $11 \mathrm{~mm}$, and 2 and $8 \mathrm{~mm}$, respectively. The incidence of the RMF in our study is also compared with the studies conducted so far in different populations reported in the literature (Table 3).

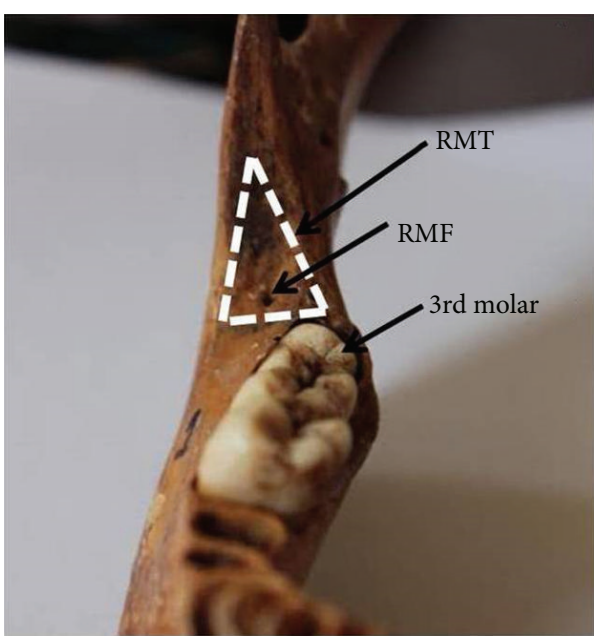

FIGURE 1: Showing the retromolar foramen (RMF) situated in the retromolar trigone (RMT) (dotted) behind the third molar tooth on right half of the mandible.

TABLE 2: Distance of RMF from 3rd molar socket, anterior border of the ramus, and lingula, respectively.

\begin{tabular}{|c|c|c|c|c|}
\hline \multirow{2}{*}{$\begin{array}{l}\text { Mandible } \\
\text { number }\end{array}$} & \multirow{2}{*}{$\begin{array}{c}\text { Side } \\
\text { examined }\end{array}$} & \multicolumn{3}{|c|}{$\begin{array}{l}\text { Distance between the retromolar } \\
\text { foramen and }\end{array}$} \\
\hline & & $\begin{array}{l}\text { 3rd molar } \\
\text { socket } \\
(\mathrm{mm})\end{array}$ & $\begin{array}{l}\text { Ant. border } \\
\text { of ramus } \\
(\mathrm{mm})\end{array}$ & $\begin{array}{c}\text { Lingula } \\
(\mathrm{mm})\end{array}$ \\
\hline 9 & Right & 4 & 5 & 8 \\
\hline 26 & Left & 7 & 10 & 6 \\
\hline 32 & Right & 8 & 3 & 6 \\
\hline 48 & Left & 11 & 3 & 6 \\
\hline 51 & Left & 6 & 4 & 2 \\
\hline 58 & Right & 8 & 8 & 2 \\
\hline 58 & Left & 4 & 5 & 3 \\
\hline 64 & Right & 6 & 11 & 4 \\
\hline 72 & Right & 4 & 9 & 2 \\
\hline 80 & Right & 8 & 9 & 5 \\
\hline 88 & Right & 5 & 8 & 6 \\
\hline 88 & Left & 5 & 9 & 4 \\
\hline 91 & Right & 6 & 4 & 3 \\
\hline 91 & Left & 5 & 4 & 5 \\
\hline \multicolumn{2}{|c|}{ Mean \pm SD } & $6.21 \pm 2.01$ & $6.57 \pm 2.82$ & $4.43 \pm 1.87$ \\
\hline \multicolumn{2}{|c|}{ Min-Max } & $4-11$ & $3-11$ & $2-8$ \\
\hline
\end{tabular}

\section{Discussion}

Considering the wide variation of incidence and the importance of this region in dental surgical procedures, the present study documented the prevalence of retromolar foramen in dry mandibles of a south-eastern Indian population sample. Percentage of the retromolar foramen occurrence in our study falls somewhere within the ranges reported from other Indian [9, 19], Turkish [20], Italian [18], Canadians of European descent [5], and Brazilian [11] populations (See Table 3). 
TABLE 3: Incidence of retromolar foramen and canal in different populations reported in the literature.

\begin{tabular}{|c|c|c|c|c|}
\hline Author & Year of study & $\begin{array}{c}\text { Number of } \\
\text { mandibles studied }\end{array}$ & Presence of retromolar foramen (\%) & Population of the study \\
\hline \multirow[t]{2}{*}{ Schejtman et al. [4] } & 1967 & 18 & $13(72)$ & Argentine aborigines \\
\hline & & 86 & $7(8.1)$ & Italian \\
\hline \multirow{3}{*}{ Ossenberg [5] } & 1987 & 94 & $3(3.2)$ & Japanese \\
\hline & 1701 & 485 & $40(8.2)$ & Eskimos \\
\hline & & 11 & $1(9.1)$ & $\begin{array}{l}\text { Canadians of European } \\
\text { descent }\end{array}$ \\
\hline Sawyer and Kiely [6] & 1991 & 234 & $18(7.7)$ & American \\
\hline Kodera and Hashimoto [15] & 1995 & 41 & $8(20)$ & Japanese \\
\hline Pyle et al. [7] & 1999 & 475 & $37(7.8)$ & $\begin{array}{l}\text { Caucasian }(n=226) \\
\text { Afro-American }(n=249)\end{array}$ \\
\hline Narayana et al. [8] & 2002 & 242 & $53(21.9)$ & Indian \\
\hline Priya and Manjunath. [9] & 2005 & 157 & $20(12.7)$ & Indian \\
\hline Lagrana et al. [16] & 2006 & 50 & $9(18)$ & Argentinean \\
\hline Bilecenoglu and Tuncer [10] & 2006 & 40 & $10(25)$ & Turkish \\
\hline Suazo et al. [11] & 2008 & 294 & $38(12.9)$ & Brazilian \\
\hline von Arx et al. [12] & 2011 & 121 & $31(25.6)$ & Swiss \\
\hline Kawai et al. [13] & 2012 & 46 & $24(52)$ & Japanese \\
\hline Rossi et al. [14] & 2012 & 222 & $59(26.6)$ & Brazilian \\
\hline Lizio et al. [18] & 2013 & $\begin{array}{c}233 \\
\text { (hemimandibles) }\end{array}$ & $34(14.6)$ & Italian \\
\hline Athavale et al. [19] & 2013 & 71 & $10(14.1)$ & Indian \\
\hline Orhan et al. [20] & 2013 & 126 & $14(11.1)$ & Turkish \\
\hline Our study & 2014 & 94 & $11(11.7)$ & Indian \\
\hline
\end{tabular}

It has been observed that the neurovascular bundle of the RMF originated in the mandibular canal and penetrated into distal lamina dura of the distal root of the third molar [4]. Dentists in particular should be aware of this accessory innervation provided by RMF in the endodontic treatment [21]. Our findings show that the distance between the 3rd molar and RMF is being within the short range of $4-11 \mathrm{~mm}$ which is comparable with the recent reports published in the literature $[8,9,19]$. This close relation of RMF with 3rd molar could lead to damage of the structures traversing through RMF during the third molar extraction and could be a reason for postoperative hematomas as described by previous authors due to rupturing of the vessels in RMF [22$25]$. The incidences reported from Indian population $[8,9,19]$ are varying from 12 to $22 \%$. The differences in the incidence of the RMF in these studies could be related to the differential origins of the Indian population. The presence of RMF with additional sensory nerve fibers was first reported by Sutton in 1974 [26]. He related the presence of this foramen to the failure of obtaining analgesia using classical anesthetic techniques [26]. Thus, the studies of the incidence of RMF are important in order to avoid failure in regional anesthetic techniques for blocking the inferior alveolar nerve and buccal nerve fibers $[15,27]$.

Singh reported that, during surgery of a third molar, he injured a nerve that crossed an unusual foramen located in the retromolar fossa [28]. After the surgery, it was found that the patient presented with paresthesia of the buccal mucosa from the retromolar region to the canine on the operated side. When this postoperative complication was investigated further, it was found that the nerve injured was a branch of the buccal nerve which crossed the RMF [28]. Anderson et al. [29] confirmed that the components in the RMF and canal are the nerves that provide innervation to the pulp of third molar, retromolar region and to the fibers of the temporalis and buccinator muscles. Thus damage to nerves of RMF and canal will disrupt the functions of temporalis and buccinator muscles. Pinsolle et al. [30] suggested that, because the RMF also allows the passage of vascular components, this may facilitate the spread of infection and metastases from the oropharynx to the blood circulation.

Keeping our measurements and observations in mind, one should be cautious when performing the following dental surgeries: third molar extraction, sagittal split osteotomies of the mandible, dieresis procedures, flap lifting, and placement of osseo-integrated implants [31].

\section{Conclusion}

This study reports the incidence of RMF in south-eastern part of Karnataka State, Indian sample, to form a basis for future better understanding of clinical and surgical practice related to the retromolar area. The RMF has great importance 
in the odontostomatological practice due to the prevalence of the pathological processes and complications related to the retromolar area involved in the practice. This could be the reason why this area is subject of a great number of surgical procedures. Knowledge of the location and contents of RMF should be carefully considered for choosing the best plan and consequently for optimizing anesthetic and surgery procedure during oral and maxillofacial procedures. We hope that this study would especially help surgeons in this part of the world to understand this area better. However, we declare that we had no availability of the radiological techniques for this present research investigations and this could be the limitation of our study. Our observations may alert the dental surgeons to conduct further studies and also to compare with studies of larger populations across the world to understand its origin and evolutionary importance.

\section{Conflict of Interests}

The authors declare that there is no conflict of interests regarding the publication of this paper.

\section{References}

[1] B. Kumar Potu, S. Jagadeesan, K. Mr Bhat, and S. Rao Sirasanagandla, "Retromolar foramen and canal: a comprehensive review on its anatomy and clinical applications," Morphologie, vol. 97, no. 317, pp. 31-37, 2013.

[2] V. Claeys and G. Wackens, "Bifid mandibular canal: Literature review and case report," Dentomaxillofacial Radiology, vol. 34, no. 1, pp. 55-58, 2005.

[3] B. K. B. Berkovitz, "Skull and mandible," in Grays Anatomy: The Anatomical Basis of Clinical Practices, S. Standring, H. Ellis, J. C. Healy, D. Jhonson, and A. Williams, Eds., p. 482, Churchill Livingstone, New York, NY, USA, 39th edition, 2005.

[4] R. Schejtman, F. C. H. Devoto, and N. H. Arias, "The origin and distribution of the elements of the human mandibular retromolar canal," Archives of Oral Biology, vol. 12, no. 11, pp. 1261-1267, 1967.

[5] N. S. Ossenberg, "Retromolar foramen of the human mandible," American Journal of Physical Anthropology, vol. 73, no. 1, pp.119$128,1987$.

[6] D. R. Sawyer and M. L. Kiely, "Retromolar foramen: a mandibular variant important to dentistry," Annals of Dentistry, vol. 50, no. 1, pp. 16-18, 1991.

[7] M. A. Pyle, T. R. Jasinevicius, J. A. Lalumandier, K. J. Kohrs, and D. R. Sawyer, "Prevalence and implications of accessory retromolar foramina in clinical dentistry," General Dentistry, vol. 47, no. 5, pp. 500-504, 1999.

[8] K. Narayana, U. A. Nayak, W. N. Ahmed, J. G. Bhat, and B. A. Devaiah, "The retromolar foramen and canal in South Indian dry mandibles," European Journal of Anatomy, vol. 6, no. 3, pp. 141-146, 2002.

[9] R. Priya and K. Y. Manjunath, "Retromolar foramen," Indian Journal of Dental Research: Official Publication of Indian Society for Dental Research, vol. 16, no. 1, pp. 15-16, 2005.

[10] B. Bilecenoglu and N. Tuncer, "Clinical and Anatomical Study of Retromolar Foramen and Canal," Journal of Oral and Maxillofacial Surgery, vol. 64, no. 10, pp. 1493-1497, 2006.
[11] G. Suazo, M. Zavando, and L. Cantín, "Retromolar canal and foramen prevalence in dried mandibles and clinical implications," International Journal of Odontostomat, vol. 2, no. 2, pp. 183-187, 2008.

[12] T. Von Arx, A. Hänni, P. Sendi, D. Buser, and M. M. Bornstein, "Radiographic study of the mandibular retromolar canal: an anatomic structure with clinical importance," Journal of Endodontics, vol. 37, no. 12, pp. 1630-1635, 2011.

[13] T. Kawai, R. Asaumi, I. Sato, Y. Kumazawa, and T. Yosue, "Observation of the retromolar foramen and canal of the mandible: a CBCT and macroscopic study," Oral Radiology, vol. 28, no. 1, pp. 10-14, 2012.

[14] A. C. Rossi, A. R. Freire, G. B. Prado, F. B. Prado, P. R. Botacin, and P. H. Ferreira Caria, "Incidence of retromolar foramen in human mandibles: Ethnic and clinical aspects," International Journal of Morphology, vol. 30, no. 3, pp. 1074-1078, 2012.

[15] H. Kodera and I. Hashimoto, "A case of mandibular retromolar canal: elements of nerves and arteries in this canal," Kaibogaku Zasshi, vol. 70, no. 1, pp. 23-30, 1995.

[16] R. Lagraña, M. Frank, M. Camacho, F. Gauna, and M. Abalo, Forámenes Accesorios del Hueso Mandibular Humano, Cátedra de Anatomía General, Facultad de Odontología Universidad Nacional del Nordeste, 2006.

[17] J. Motta Junior, F. Maria de Lourdes, R. A. Matheus, and G. A. V. Stabile, "Forame retromolar: sua repercussão clínica e avaliação de 35 mandíbulas secas," Revista de Odontologia da UNESP, vol. 41, no. 3, pp. 164-168, 2012.

[18] G. Lizio, G. A. Pelliccioni, G. Ghigi, A. Fanelli, and C. Marchetti, "Radiographic assessment of the mandibular retromolar canal using cone-beam computed tomography," Acta Odontologica Scandinavica, vol. 71, no. 3-4, pp. 650-655, 2013.

[19] S. A. Athavale, M. Vijaywargia, R. Deopujari, and S. Kotgirwar, "Bony and cadaveric study of retromolar region," People's Journal of Scientific Research, vol. 6, no. 2, pp. 14-18, 2013.

[20] A. I. Orhan, K. Orhan, S. Aksoy et al., "Evaluation of perimandibular neurovascularization with accessory mental foramina using cone-beam computed tomography in children," Journal of Craniofacial Surgery, vol. 24, no. 4, pp. e365-e369, 2013.

[21] M. C. Madeira, Anatomia do Dente, Sarvier, São Paulo, Brazil, 6th edition, 2010.

[22] B. Azaz and J. Lustmann, "Anatomical configurations in dry mandibles," British Journal of Oral Surgery, vol. 11, no. 1, pp. 1-9, 1973.

[23] G. J. Petruzzelli, F. K. Knight, D. Vandevender, J. I. Clark, and B. Emami, "Posterior marginal mandibulectomy in the management of cancer of the oral cavity and oropharynx," Otolaryngology - Head and Neck Surgery, vol. 129, no. 6, pp. 713$719,2003$.

[24] T. Muto and M. Kanazawa, "Mandibular reconstruction using the anterior part of ascending ramus: report of two cases," Journal of Oral and Maxillofacial Surgery, vol. 55, no. 10, pp. 1152-1156, 1997.

[25] I. S. Galdames, "Lower third molar region," International Journal of Morphology, vol. 30, no. 3, pp. 970-978, 2012.

[26] R. N. Sutton, "The practical significance of mandibular accessory foramina," Australian Dental Journal, vol. 19, no. 3, pp. 167173, 1974.

[27] E. Kaufman, N. J. Serman, and P. D. Wang, "Bilateral mandibular accessory foramina and canals: a case report and review of the literature," Dentomaxillofacial Radiology, vol. 29, no. 3, pp. 170-175, 2000. 
[28] S. Singh, "Aberrant buccal nerve encountered at third molar surgery," Oral Surgery Oral Medicine and Oral Pathology, vol. 52, no. 2, p. 142, 1981.

[29] L. C. Anderson, T. F. Kosinski, and P. J. Mentag, "A review of the intraosseous course of the nerves of the mandible," The Journal of oral Implantology, vol. 17, no. 4, pp. 394-403, 1991.

[30] V. Pinsolle, Y. Truilhe, C. Majoufre, V. Michelet, and J. Pinsolle, "Posterior marginal mandibulectomy for cancer of the oral cavity and oropharynx. An experience of 14 clinical cases," Annales de Chirurgie Plastique et Esthetique, vol. 42, no. 3, pp. 223-227, 1997.

[31] J. P. Reyneke, P. Tsakiris, and P. Becker, "Age as a factor in the complication rate after removal of unerupted/impacted third molars at the time of mandibular sagittal split osteotomy," Journal of Oral and Maxillofacial Surgery, vol. 60, no. 6, pp. 654659, 2002. 

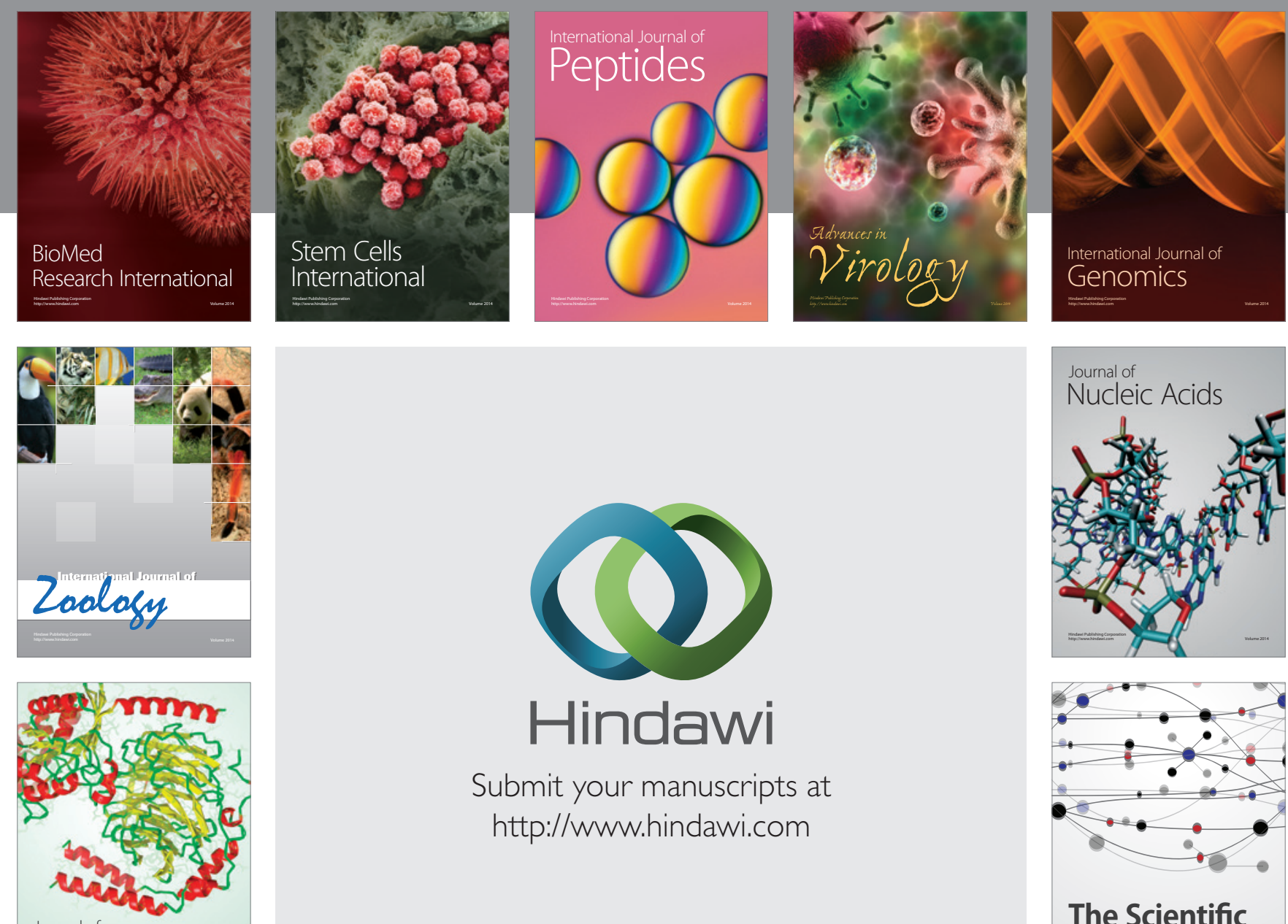

Submit your manuscripts at

http://www.hindawi.com

Journal of
Signal Transduction
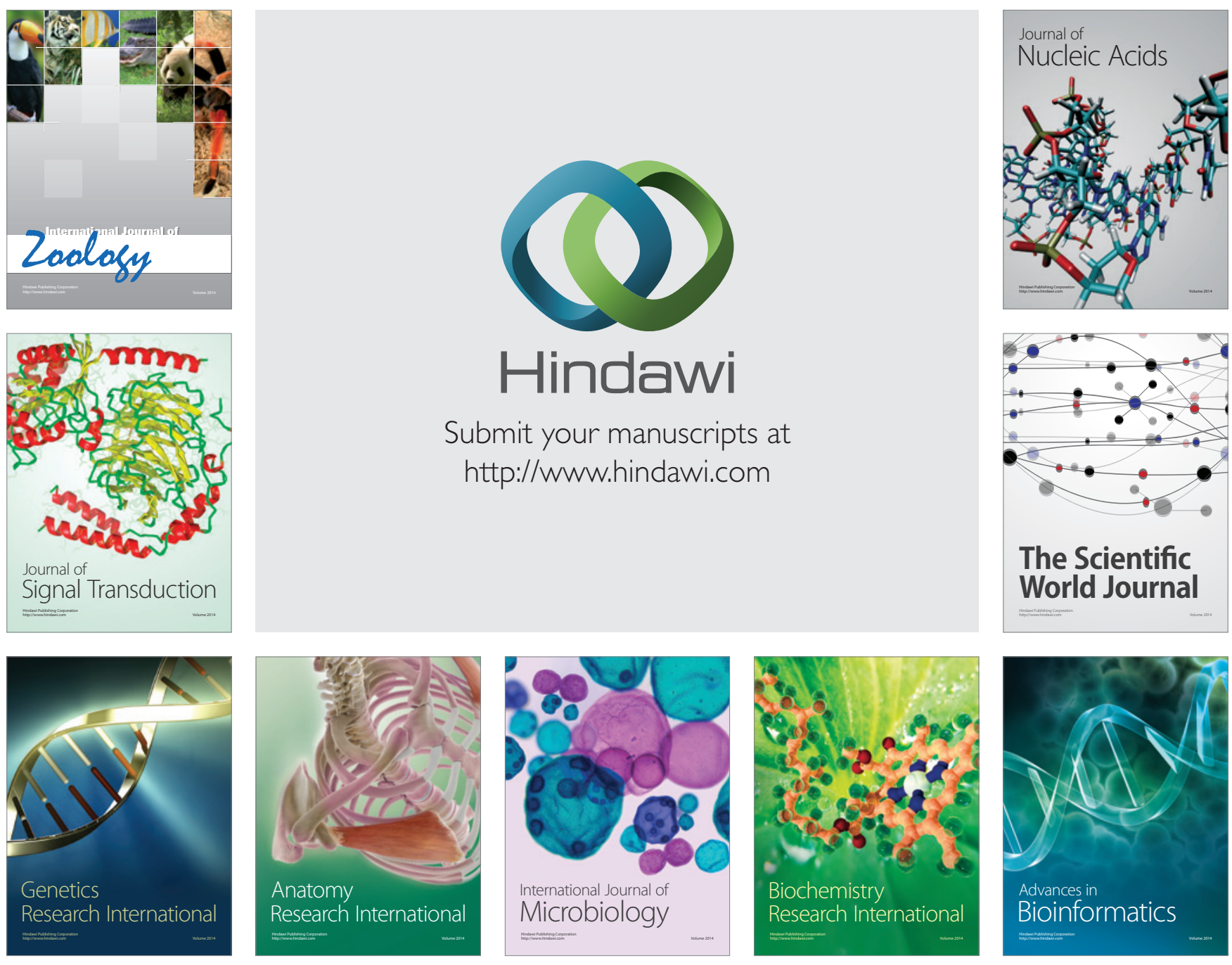

The Scientific World Journal
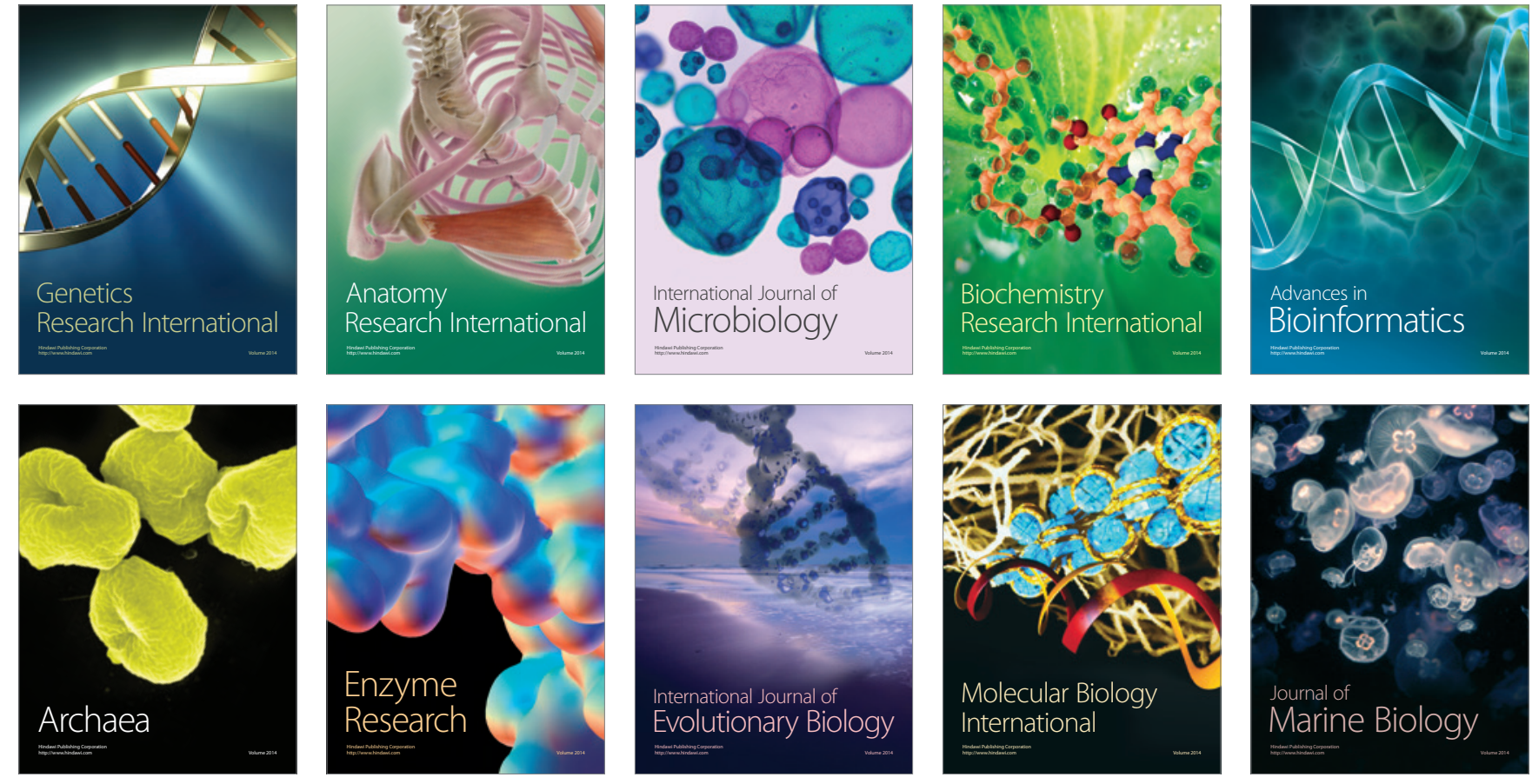